\title{
Brood removal or queen caging combined with oxalic acid treatment to control varroa mites (Varroa destructor) in honey bee colonies (Apis mellifera)
}

\author{
Aleš Gregorc ${ }^{1,2}$, Mohamed Alburaki ${ }^{3}$, Chris Werle ${ }^{4}$, Patricia R. KNIGHT ${ }^{1}$, \\ John ADAMCZYK ${ }^{4}$ \\ ${ }^{1}$ Center for Costal Horticulture Research, Mississippi State University, Poplarville, MS, USA \\ ${ }^{2}$ Agricultural Institute of Slovenia, Hacquetova 17, 1000, Ljubljana, Slovenia \\ ${ }^{3}$ Entomology and Plant Pathology Department, West Tennessee Research and Education Center, The University of \\ Tennessee, Jackson, TN 38301, USA \\ ${ }^{4}$ ARS, Thad Cochran Southern Horticultural Research Laboratory, USDA, Poplarville, MS 39470, USA
}

Received 14 March 2017 - Revised 19 May 2017 - Accepted 22 June 2017

\begin{abstract}
Few studies of honey bee colonies exist where varroa mite control is achieved by integrating broodless conditions, through either total brood removal or queen caging, in combination with oxalic acid (OA) applications. We observed significant varroa mortality after total brood removal or caging the queens and OA applications in broodless colonies, as well as in colonies with brood that received four consecutive OA applications. In laboratory tests, we recorded higher mortality of caged bees exposed to Apistan ${ }^{\circledR}$ compared to oxalic acid or untreated control bees. However, this mortality is not believed to negatively impact the colony. We therefore recommend combining OA applications with artificial broodless colony conditions achieved either by brood removal or queen caging as an effective management strategy for varroa mites.
\end{abstract}

varroa control / oxalic acid / cages / sugar shake / Varroa destructor

\section{INTRODUCTION}

Maintenance of healthy honey bee (Apis mellifera L.) colonies is dependent upon the control of the parasitic mite Varroa destructor Anderson and Truemann (varroa). While untreated colonies collapse within a few years, use of acaricides in beekeeping should be minimized to avoid build-up of chemical residues and their byproducts in honey and wax (Wallner 1999) and to reduce the potential development of acaricide resistance (Ruijter 1994). There is little data to discourage use of "natural acaricides" such as organ-

Corresponding author: A. Gregorc, ag2346@msstate.edu

Manuscript editor: Peter Rosenkranz ic acids (Milani 1999), which do not accumulate in wax and have toxicologically insignificant residue build-up in honey (Imdorf et al. 1996). Natural, nontoxic organic acids including oxalic acid (OA) (Liebig 1998; Al Toufailia et al. 2015) have been successfully tested as miticides and are increasingly being used by beekeepers (Coffey and Breen 2016; Charrière and Imdorf 2002).

Use of different OA solutions for varroa control (varroacide) has been increasing due to its high efficacy and low risk of hive contamination, and it is often applied to colonies by trickling a solution of OA and sugar water between the frames of the hives (Charrière and Imdorf 2002). Charrière and Imdorf (2002) also evaluated that OA is effective in broodless colonies as OA affect only phoretic mites present on adult hive bees. The effectiveness of OA trickling in honey bee colony is limited to approx. 5 days; therefore, it is needed to repeat 
OA trickling (Gregorc and Planinc 2004). The recommended application rate per hive is $50 \mathrm{~mL}$ of OA solution, with reports of several OA dihydrate + sugar water concentrations, including $3.4 \% \mathrm{OA}+47.6 \%$ sucrose, $3.7 \% \mathrm{OA}+27.1 \%$ sucrose, and $3.0 \% \mathrm{OA}+32.0 \%$ sucrose (both substances are quoted in weight/weight, $w / w$ ) (Nanetti 1999; Gregorc and Smodiš Škerl 2007; Charrière and Imdorf 2002). Higher concentrations of OA mixed in sugar water will exhibit greater varroa efficacy than solutions with lower concentrations, with a similar toxicity response expressed in honey bees (Charrière and Imdorf 2002). In one study, honey bees exposed to the recommended dose of $100 \mu \mathrm{g}$ of OA per adult bee survived longer than $72 \mathrm{~h}$, and mortality did not differ from the untreated control (Aliano et al. 2006). Thus, it is thought that the dosage of OA dihydrate in solution with sugar water has an impact on mortality rates in mites as well in bees (Milani 2001; Charrière et al. 2004; Al Toufailia et al. 2015). Oxalic acid is a natural constituent of honey with extensive research on its acaracidal efficacy both alone and in combination with a variety of biotechnical varroa control methods (Giacomelli et al. 2016; Gregorc et al. 2016). These biotechnical methods can include removal of drone brood (Delaplane et al. 2005) or caging the queen, in both cases creating an artificial brood interruption period (Rosenkranz et al. 2010; Giacomelli et al. 2016). Queen caging in combination with acaricide applications can increase the efficacy of varroa control to $>96 \%$ (Nanetti et al. 2012; Pietropaoli et al. 2012; Giacomelli et al. 2016). Temporarily caging the queen can also be combined with removal of capped or un-capped brood, which has led to $>93 \%$ control efficacy (Calis et al. 1999). While OA is a highly effective miticide (Nanetti 1999), at more highly concentrated solutions $(>1 \% \mathrm{OA})$, there is evidence for some colony weakening (Charrière 2001; Toomemaa et al. 2010). Thus, we believe $\mathrm{OA}$ is suitable for the control of varroa, as long as the recommended dosage rate is used based on the local climatic and beekeeping conditions.
The first objective of this study was to determine the comparative toxicity of three different solutions of OA dihydrate in sugar water, which is used as varroacide, on caged adult worker bees under laboratory conditions. The second objective was to determine effectiveness of successive applications of a $2.9 \% \mathrm{OA} / 31.95 \%$ sugar-in-water solution, in combination with artificial brood interruption by either (1) queen caging, (2) total brood removal, or (3) no brood interruption but with three consecutive OA applications. Results from these experiments will promote a greater awareness of the options available to beekeepers for the effective control of varroa.

\section{MATERIALS AND METHODS}

A laboratory experiment was performed in order to establish the comparative toxicity of three oxalic acid solutions and tau-fluvalinate (Apistan ${ }^{\circledR}$ ) on adult worker bees collected from honey bee colonies. Selected OA solution from the laboratory test was then used in a field trial in combination with either total brood removal or queen caging in order to test efficacies for varroa control in honey bee colonies.

\subsection{Laboratory experiment}

Worker bees from three colonies were brushed from their combs, mixed, and caged in 473-mL disposable plastic cups (lower diameter $8 \mathrm{~cm}$ and height $13.5 \mathrm{~cm}$; item no. 416, Fineline, Middletown, NY). Cups (Evans et al. 2009) were modified with approx. eighty 3-mm aeration holes drilled in sides, as well as one 12-mm hole drilled in both the tops (for adding water supply) and sides (for removal of dead bees or adding diet when necessary). Bees in each group of cages were provided with water and food (Pro Winter Patty, Mann Lake Ltd., Hackensack, MN), ad libitum. Five separate treatment groups were established, with six cages of 20 bees for each treatment. Treatments were as follows: (1) a 40$\mu \mathrm{L}$ solution of $3.4 \%$ OA (CAS no. 6153-56-6; Sigma-Aldrich, St. Louis, MO) and $47.6 \%$ 
sucrose (10 g OA dihydrate, $100 \mathrm{~g}$ sucrose, $100 \mathrm{~g}$ water); (2) $40 \mu \mathrm{L}$ solution of $3.7 \% \mathrm{OA}$ and $27.1 \%$ sucrose (7.6 g OA-dehydrate, $38 \mathrm{~g}$ sucrose, and $100 \mathrm{~g}$ water); (3) $40 \mu \mathrm{L}$ solution of $3.0 \% \mathrm{OA}$ and $32.0 \%$ sucrose (6.5 g OA-dehydrate, $50 \mathrm{~g}$ sucrose, and $100 \mathrm{~g}$ water) solution; (4) a $1 \times 1-\mathrm{cm}$ piece of Apistan ${ }^{\circledR}$ (Vita, Basingstoke, UK) fixed to a push pin, ensuring exposure to bees from both sides; and (5) was an untreated control, receiving the same quantities of the $32 \%$ sugar solution. Volume of OA solution applied to caged adults was calculated according to number of bees per cage, by extrapolating data from repeatedly treated colonies receiving 5-mL OA solution per occupied space between frames (Gregorc et al. 2016).

Solutions of OA were applied three times: at the beginning of the experiment and again on day 4 and day 8 . The toxicity evaluation period for caged bees was 13 days in total, in order to compare adult bee mortality after exposure to multiple OA applications or continuous Apistan ${ }^{\circledR}$ exposure. For the first two OA applications, all cages in the first, second, and third treatment groups received $40 \mu \mathrm{L}$ each of their respective OA solution, and for the third OA application, some proportion of bees died. They received $20 \mu \mathrm{L}$ each of solution. The control group received the same volumes of sugar solution. Control and OA solutions were delivered by a pipette through the 12$\mathrm{mm}$ side opening of the assay cup; the $40-\mu \mathrm{L}$ volume was applied with eight to nine small drops while the $20-\mu \mathrm{L}$ volume was split into four to five drops. This was meant to imitate the topical OA treatment of the field colonies, ensuring direct contact with bees. The cages were kept in a darkened room maintained at $28( \pm 1)^{\circ} \mathrm{C}$ and $65 \% \mathrm{RH}$, and dead bees were counted and removed every $24 \mathrm{~h}$.

\subsection{Field experiment}

We used 22 honey bee colonies to test control of varroa in the field, after either caging queens, total removal of brood, or repeated OA treatments. All colonies were established at the apiary station on the Mississippi State University's McNeill
Subunit in McNeill, MS (30 39' 46" N, 89 38' $\left.01^{\prime \prime} \mathrm{W}\right)$ using Italian-bred queens. Experimental colonies were queen right and fully developed and were housed in 10-frame Langstroth deep boxes (Dadant \& Sons, Inc., IL) with plastic comb foundations. Before the experiment, colonies were equalized to occupy six to eight brood combs. Corrugated plastic bottom boards (Dadant \& Sons, Inc., Hamilton, IL) were inserted in order to record mite mortality, with wire screens installed above the boards to prevent bees from coming into contact with debris. Hives were placed on the wood pallets, and during experiment, we had not observed ants removing varroa mites from bottom boards. On sampling dates, numbers of dead mites were recorded and bottom boards were cleaned. Levels of natural mite "drop-down" were recorded four times prior to treatment applications (from 22 March to 22 April) and 11 times after applications (from 22 April to 14 July; Figure 2). All colonies were managed in the same manner until April 22, when colonies were randomly assigned to three experimental groups: brood removal, queen caging, or OA-treated colonies.

Seven colonies of group 1 were used for the total brood removal experiment. After opening the hive, bees were brushed from all opened or sealed brood combs back into their original hive boxes, with adding comb foundations, and with all queens identified and left within their colonies. Brood combs were then removed from the apiary, and adult bees in the now-broodless colonies were treated with OA trickling. In the seven colonies of group 2, queens were caged for 25 days, and after broodless conditions were achieved, OA trickling was conducted on 17 May. Our novel queen cages were made from 19-mm plywood, with dimensions $9 \times 15 \mathrm{~cm}$. Two holes (diameter $84 \mathrm{~mm}$ ) were drilled into the plywood and covered with 3.1-mm metal mesh screen on both sides to keep the queen caged in the cage volume of $194 \mathrm{~cm}^{3}$. Another hole (diameter $10 \mathrm{~mm}$ ) was drilled into the cage edge for queen insertion and release at the end of experiment (Figure 1). All colonies from group 2 were examined every 7-10 days, with any newly built queen cells removed. Lastly, the eight 


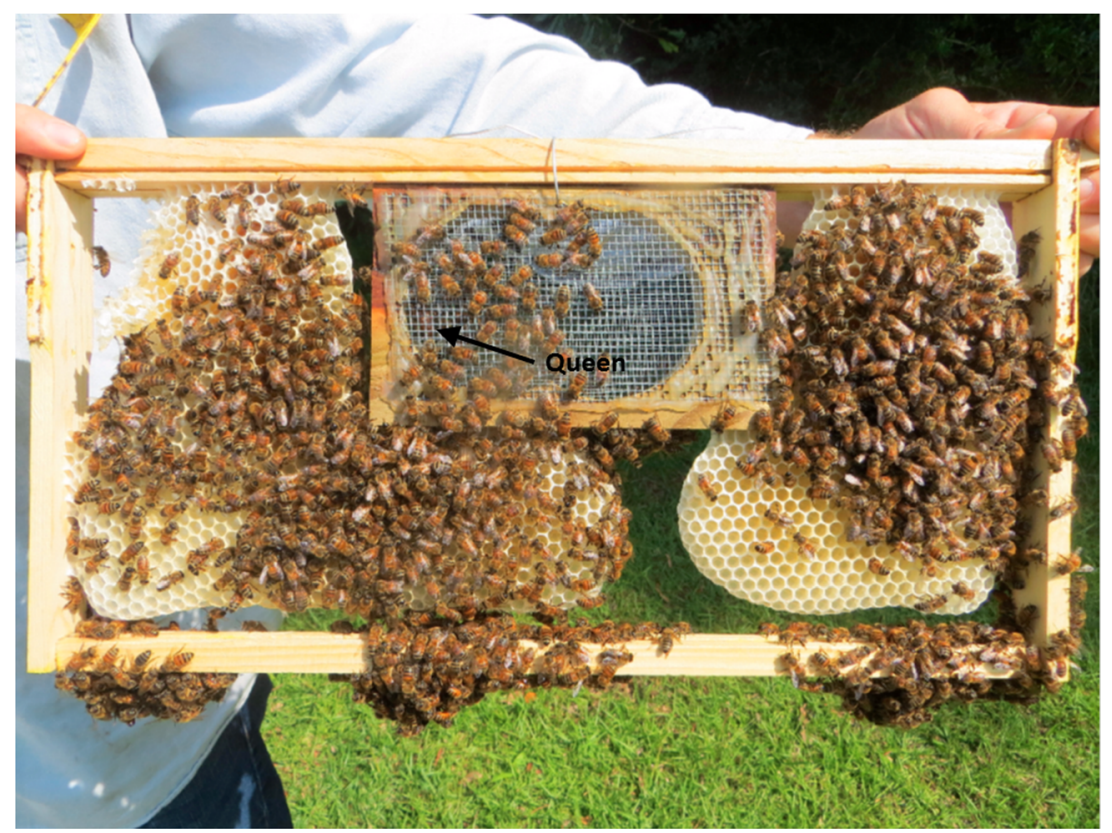

Figure 1. Photograph of homemade cage, inserted into standard comb frame.

brooded OA-treated colonies of group 3 were treated with $\mathrm{OA}$ four times in order to measure the effect of brood manipulation on varroa control. On 17 May, all experimental colonies were treated simultaneously with OA solutions. Dead varroa on a bottom boards were normally counted 3 and 7 days after each AO application.

Each OA-treated colony received $5 \mathrm{~mL}$ of a $2.9 \% \mathrm{OA}$ and $31.9 \%$ sucrose-in-water solution $(w / w)$ per occupied space between combs. Treatments were prepared using oxalic acid dihydrate (Sigma-Aldrich), sucrose (sugar), and de-mineralized water (Gregorc and Planinc 2001) and were trickled over the combs, in situ, using a syringe. To determine relative infestation levels (number of mites/ bee) in experimental colonies, adult bees were collected for sugar shake tests (Gregorc et al. 2016) both prior to and following treatments on 22 April and on 25 May, respectively. The outside temperature and humidity during the sugar shakes were $T=21{ }^{\circ} \mathrm{C}$ and $\mathrm{RH}=70 \%$ on 22 April and $T=27^{\circ} \mathrm{C}$ and $\mathrm{RH}=72 \%$ on 25 May. Temperatures during OA applications ranged from $19{ }^{\circ} \mathrm{C}$ on April 22 to $23{ }^{\circ} \mathrm{C}$ on 17 May. After the last OA treatment on 17 May and sugar shake on 25 May, two Apistan ${ }^{\circledR}$ strips were placed in each experimental colony in order to detect any remaining Varroa mites (Figure 2).

\subsection{Statistical analysis}

Statistical analysis and figure generation were conducted with $\mathrm{R}$ environment ( $\mathrm{R}$ Core Team 2011). Variables of this study included (1) bee mortality, (2) varroa counts, (3) brood removal, and (4) queen caging. All variables were first tested for normality using the Shapiro-Wilk test and were not normally distributed. We attempted to normalize our data by log-transformation and repeated the Shapiro-Wilk test with $Q-Q$ plots to visualize the data distribution. Although log transformation failed to normalize our dataset, per date data were close to normality, and analysis of variance (ANOVA) was carried out at a $95 \%$ confidence level. ANOVA is not very sensitive to moderate deviations from normality (Glass et al. 1972; Harwell et al. 1992; Lix et al. 1996), and significant results were doublechecked with nonparametric tests. Principal 
1) Cage experiment: 30 bee cages / 13 day-test

\begin{tabular}{|l|}
\hline \multicolumn{1}{|c|}{ Group 1} \\
\hline 20 bees \\
$(40 \mu \mathrm{l}):$ \\
$3.4 \%$ OA \\
$47 \%$ sucrose \\
\hline
\end{tabular}

\begin{tabular}{|c|}
\hline \multicolumn{1}{|c|}{ Group 2} \\
\hline 20 bees \\
$(40 \mu \mathrm{l}):$ \\
$3.7 \%$ OA \\
$27 \%$ sucrose \\
\hline
\end{tabular}
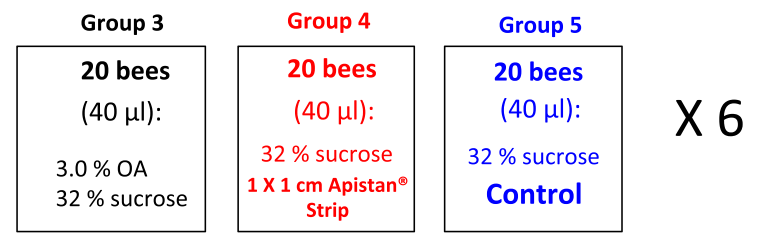

\section{2) Field experiment: 22 honeybee colonies}

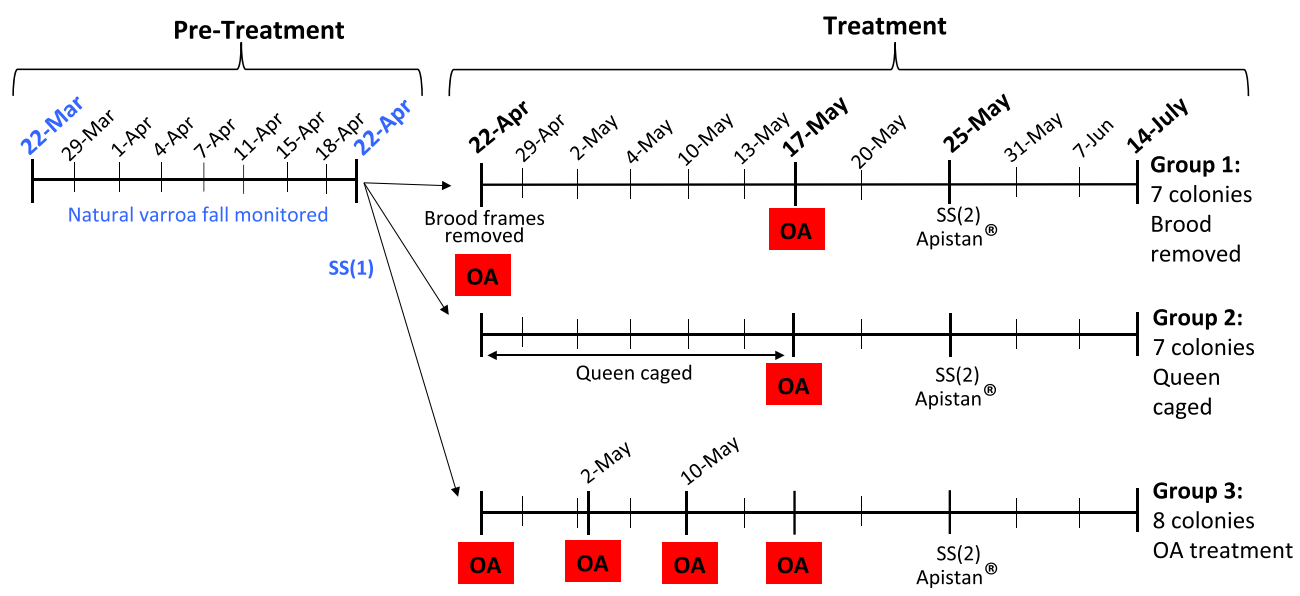

Figure 2. Timelines of both the laboratory and field experiments. The laboratory toxicity experiment lasted 13 days, with five treatments and six replicates. The field experiment was divided into pre- (22 March-22 applied for each group.
April) and treatment periods, with the date of each varroa count, sugar shake (SS 1, April 22; SS 2, May 25) and Apistan ${ }^{\circledR}$ treatment (25 May). OA indicates the dates at which oxalic acid treatments were component analyses (PCA) were carried out using "Devtools" Package as well as "FactoMine" to calculate the percentage of the variability expressed in three-dimensional space and to study the clusters and groups based on their overall resemblance. Outlier values were not omitted from the datasets and were treated as such to fairly assess the experimental variables.

\section{RESULTS}

\subsection{Laboratory experiment}

Measurements of caged bee mortality from the three OA treatments were made over the course of the 13-day laboratory experiment and again at
4 days after the last OA treatment. These were compared against mortality from the Apistan $囚-$ treated group and the control group. Observation time of the 13-day included caged bee mortality between OA treatments and 4 days after the last OA treatment as well as mortality induced by the Apistan ${ }^{\circledR}$ strips and the control treatment. None of the OA concentrations differed significantly in bee mortality (Figure 2), and the Apistan ${ }^{\circledR}$-treated group was the only one that exhibited significantly higher bee mortality compared to the control $(F=2.7, n=390, d f=4 ; P=0.02)$ (Figure 3).

\subsection{Field experiment}

The 22 experimental colonies showed no significant differences in natural varroa mortality 


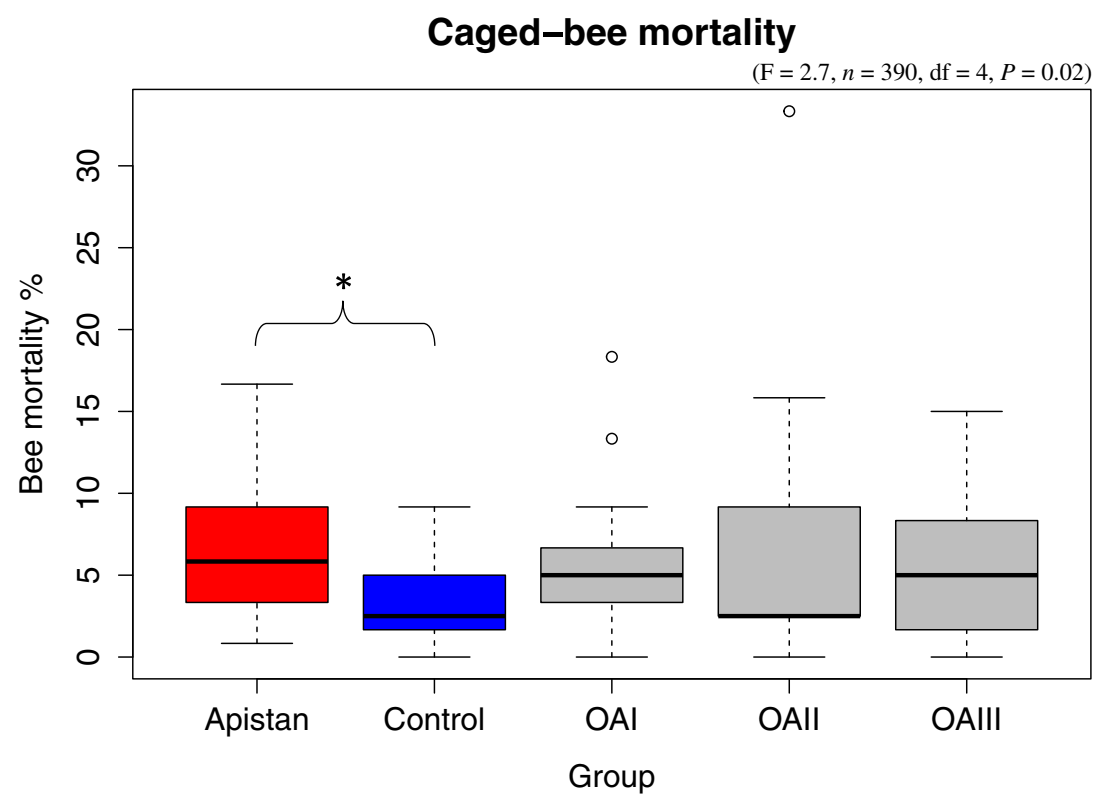

Figure 3. Cumulative percentages of caged bee mortality after 13 days from five treatment groups, with significant differences $(P<0.05)$ between the Apistan ${ }^{\circledR}$-treated group and the control. OA treatment solutions were OA I, 3.4\% OA and $47.62 \%$ sucrose; OA II, 3.37\% OA and $27.1 \%$ sucrose; and OA III, 2.97\% OA and $31.95 \%$ sucrose in water solution, while the Apistan ${ }^{-}$-treated group received a $1 \times 1-\mathrm{cm}$ strip per 20 bees.

prior to treatment applications (22 March to 22 April), whether compared across hives or future experimental groups $(F=2.9, n=198, d f=2$, $P=0.06$ ) (Figure 4). PCA individual and variable map factors revealed weak variability (27 and $19 \%$ ) expressed on both axes 1 and 2, respectively (Figure 4). On the other hand, no hive clustering from any form can be seen as a result of the variables' projection on the first two axes (1 and 2). Post-treatment results showed significant differences in varroa mortality among our three treatment groups (brood removal, queen caging, repeated OA treatment) at different times (Figure 5). The OA treatment applied on 22 April to brood removal and OA-treated colonies showed a significant effect on varroa mortality, compared with the non-treated caged queen colonies (post-treatment $1 ; P<0.001$ ) (Figure 5). OA effects persisted until the second varroa count (post-treatment 2), showing a continuous significant effect on varroa mortality $(P<0.001)$. However, in the second OA treatment for the repeated OA-treated colonies, mite mortality was reduced in comparison to previous treatment but was still significant
$(P<0.05)$. The third OA application on the OAtreated colonies (post-treatment 5 ) had no effect on reducing varroa infestation compared to the other two groups. On 17 May, when all colonies were simultaneously treated with OA, only the caged queen colonies showed significantly higher varroa mortality $(P<0.01)$ in comparison to colonies from the other two treatment groups (Figure 5). The final treatment with Apistan indicated that, among the three treatment groups, only colonies with brood removed had significantly $(P<0.05)$ higher varroa mortality. No caged queen mortality was observed during experiment, and all queens were released and they continued laying eggs.

The dynamic of varroa mortalities in colonies based on the three different treatment methods used in our study is remarkably different. The overall mite post-treatment mortality did not differ among groups (Figure 6). However, the pattern of varroa mortalities clearly differed, and the PCA discriminated two major groups (brood removal and queen caging + OA treatment). Similarly, no overall differences in varroa load were recorded 

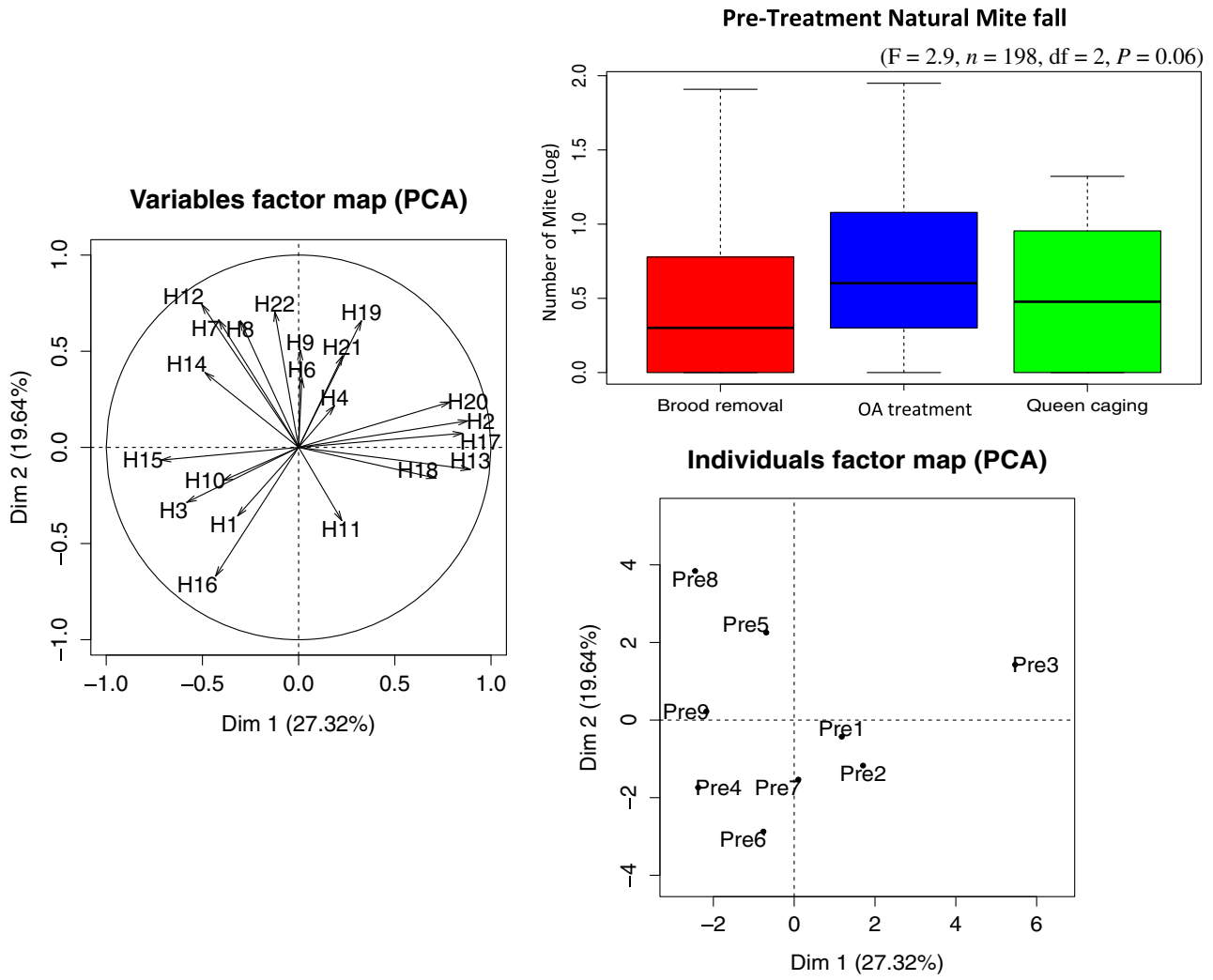

Figure 4. Principal component analysis $(P C A)$ and ANOVA analyses of pre-treatment, natural varroa mortality levels for the 22 experimental colonies, treated by both colony and subsequent treatment groups (brood removal, OA treatment, queen caging). None of the analyses show significant pretreatment differences among colonies or groups.

among the three groups between 22 April and 17 May.

Sugar shake diagnostic tests were performed in both the pretreatment (22 April) and posttreatment periods (25 May) (Figure 7). Using a count of no. mites per 100 bees as a calculation of percent infestation, relative varroa infestation levels of adult bees were estimated at $3.22 \%$ $( \pm 2.51 \%)$ pretreatment and $0.25 \%( \pm 0.51 \%)$ post-treatment, representing a statistically significant reduction $(P<0.001)$ in varroa infestation from each treatment group (Figure 7). There were also significant differences in mite reduction determined between the treatment groups $(P<0.001)$. Post-treatment sugar shakes demonstrated that on average $86.02 \%( \pm 26.69 \%)$ of mites were killed in experimental colonies - data not shown.

\section{DISCUSSION}

In this study, we demonstrated that caged bees treated with each of the three different OA solutions experienced some additional bee mortality, but after exposure to Apistan® strips, there was significantly higher mortality as compared with untreated control bees. We also found that three biotechnical procedures (brood removal, queen caging, or repeated OA applications over bees "in situ") provided highly effective varroa control in queen right colonies. Using natural mite mortality as a measurement, we determined that infestation levels between treatment groups were similar, so there was no bias prior to treatments. While some researchers have determined a weak correlation between natural mite mortality vs. mortality due to chemical treatments (Milani 1990), others 

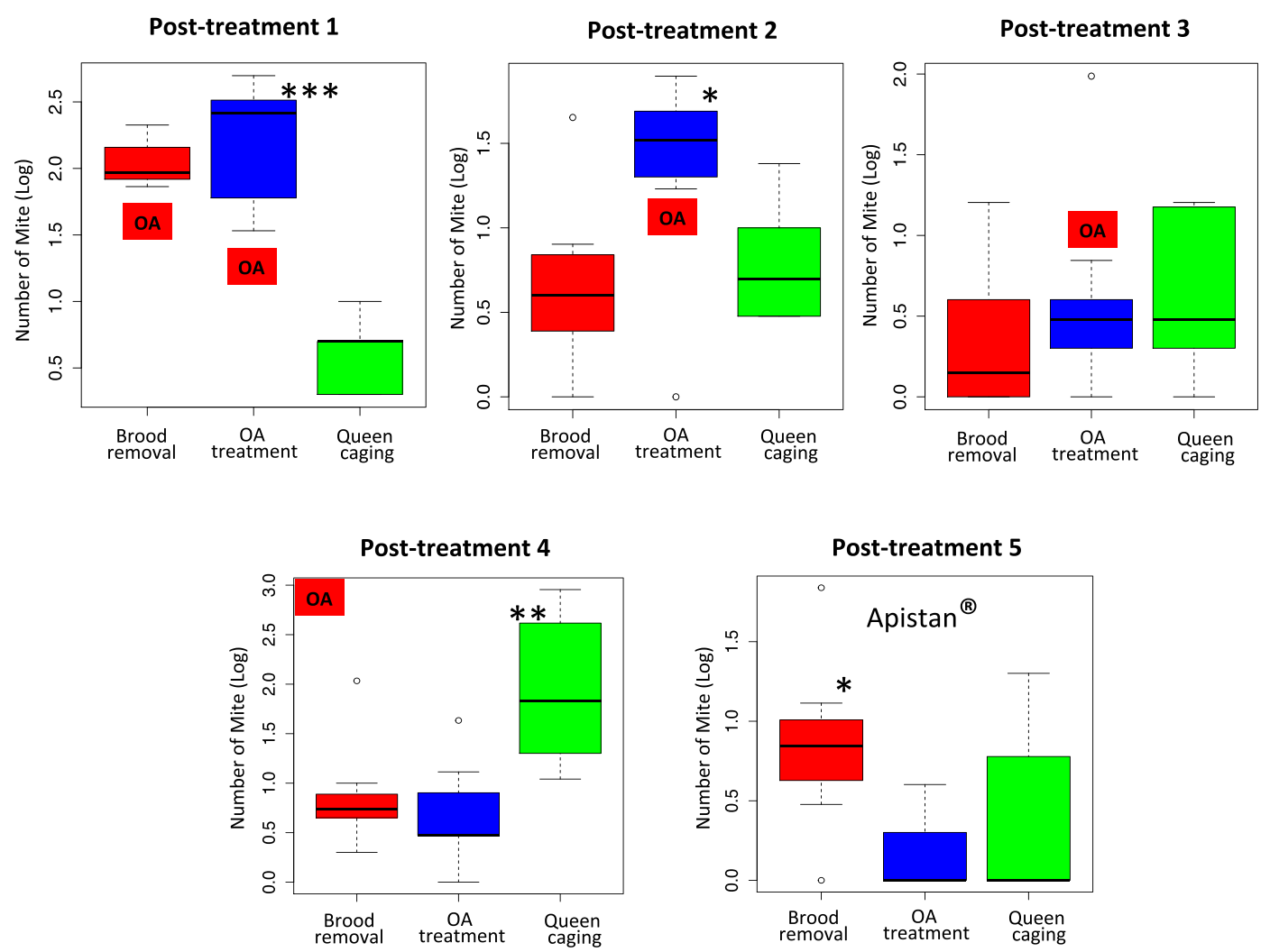

Figure 5. Number of varroa killed during the post-treatment experiment, separated by date and treatment (brood removal, OA treatment, queen caging). OA indicates the date and treatment group where oxalic acid was applied. Post-treatments 1 and 2 denote varroa mortality at the four OA treatment dates, while post-treatment 5 is the varroa mortality after Apistan treatment. ANOVA levels of significances are $P<0.05^{*}, P<0.01^{* *}, P<0.001^{* * *}$.

demonstrating a strong correlation provide evidence that measurements of natural mite mortality can be useful as a diagnostic tool (Brødsgaard and Brødsgaard 1998; Branco et al. 2006). In our experiment, the post-treatment measurement of varroa mortality increased significantly in comparison to pretreatment natural mortality, becoming evident after OA applications in colonies both with and without brood. We have not included "untreated control" colonies in order to reduce the number of untreated colonies in the field experiment and thus reduced potential varroa drifting between colonies from different treatment groups.

Sugar shake diagnostic tests performed both before and after treatment applications are predictably effective in estimating mite infestation levels (Gregorc et al. 2016; Fakhimzadeh 2000; Macedo and Ellis 2000). After completing all treatment applications, sugar shakes revealed significant reductions in mite infestations for all experimental groups, equivalent to an $88 \%$ reduction overall. However, the experimental treatments were still inferior to Apistan ${ }^{\circledR}$ strips, where mite reductions ranged from 95 to $99 \%$. Prior reports include similar results, with a $96 \%$ reduction from a single OA treatment when combined with queen caging (Pietropaoli et al. 2012) and 97\% when caging was combined with thymol-based Apiguard (Giacomelli et al. 2016). Previous results from our lab demonstrated that, on their own, either consecutive applications of OA in colonies with brood or queen caging for 25 days plus an OA application, provided insufficient mite reductions, and that only the integration of these treatments with additional measures would ensure adequate 
Overall post-treatment mite fall

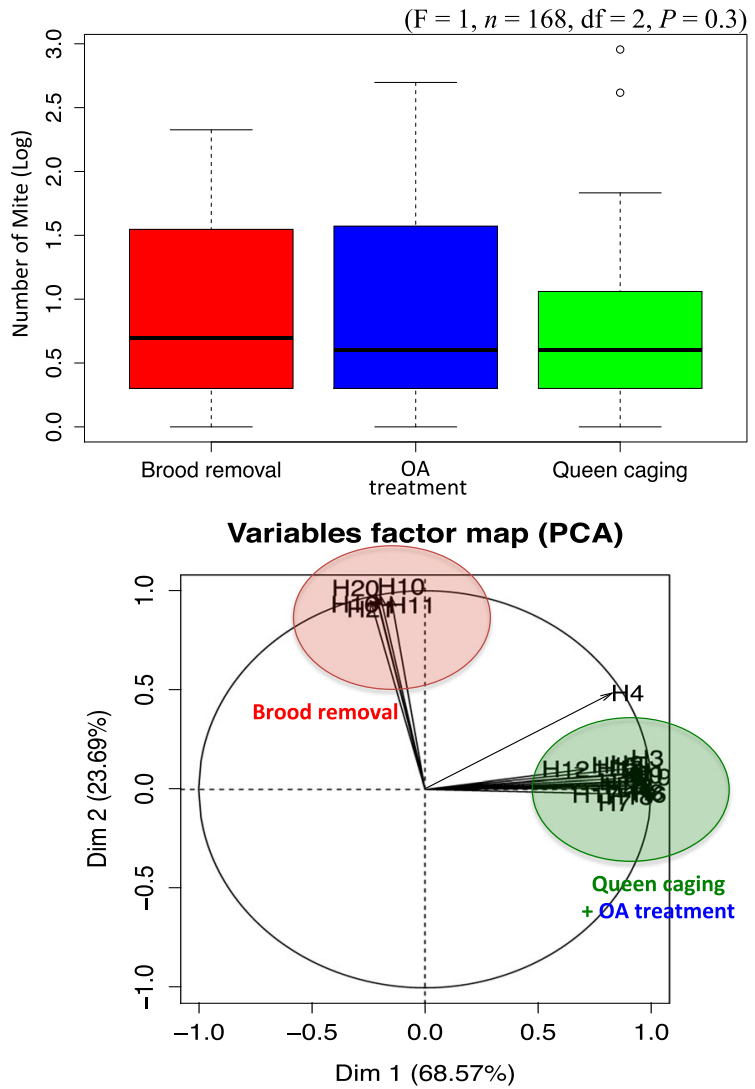

Varroa load / 22-Apr to 17-May
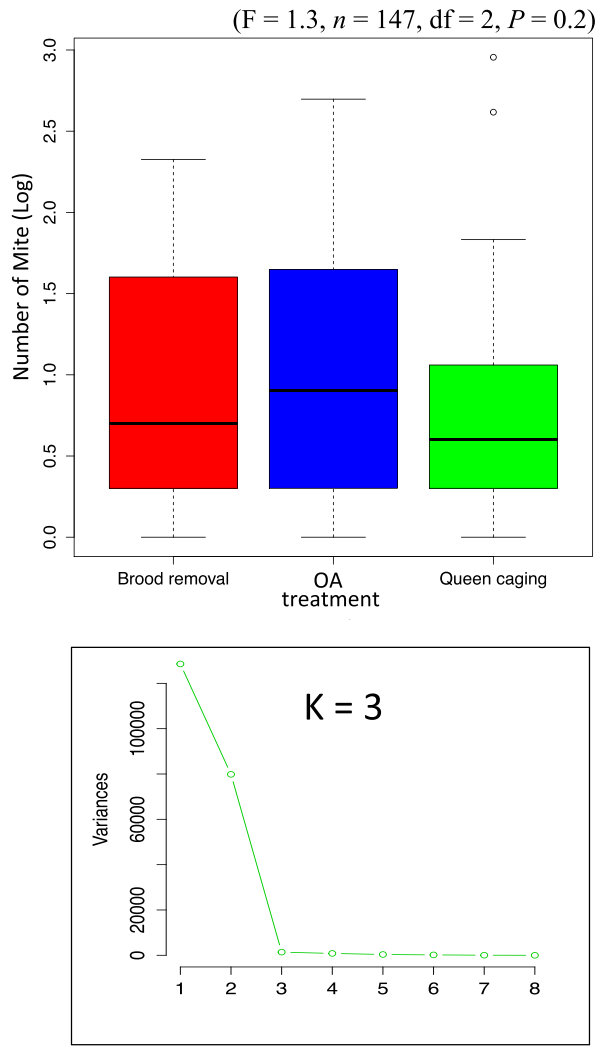

Figure 6. PCA differentiation between brood removal and queen caging, with variability (68.5\%) expressed on axis 1. No significant differences were found among treatment groups for both overall post-treatment (22 April to 14 July) and prior to the final OA treatment (22 April to 17 May). PCA variables factor map clearly distinguished between two major groups of hives, (1) brood removal and (2) queen cages + OA treatment.

varroa control (Gregorc et al. 2016). Further evidence from multiple tests in Italy has revealed $\geq 95 \%$ varroa control when queen caging has been combined with OA applications, and this method has now been accepted as a standard treatment protocol (Nanetti et al. 2016). It is interesting that, in colonies with brood, our four consecutive OA treatments were highly effective as compared with previous tests, where mortality ranged widely from 44 to $70 \%$ (Smodiš Škerl et al. 2011). With capped brood present, reports of OA efficacy have been even more variable, ranging from 24 to $95 \%$ (Mutinelli et al. 1997). Because of the potential development of mite resistance to Apistan ${ }^{\circledR}$ (Al Toufailia and Ratnieks 2016; González-Cabrera et al. 2016), our results may represent an overestimate of mite control efficacy. In contrast, results from our sugar shakes may represent underestimates since mites protected within sealed brood cells at the time of the sugar shake may have been killed later by Apistan®. It is interesting that the last OA treatment (17 May) induced the highest varroa mortality in colonies with caged queens, whereas in colonies with total brood removal, more mites were killed after the first OA treatment. The latest colonies were without brood at the time of highly effective OA application. In the OA-treated colonies, similar mite mortality was observed from each consecutive OA application. It is notable that each treatment group provided very effective mite control, and each could be easily applied in field conditions. Our results 


\section{Sugar Shake / Pre and Post-Treatment}

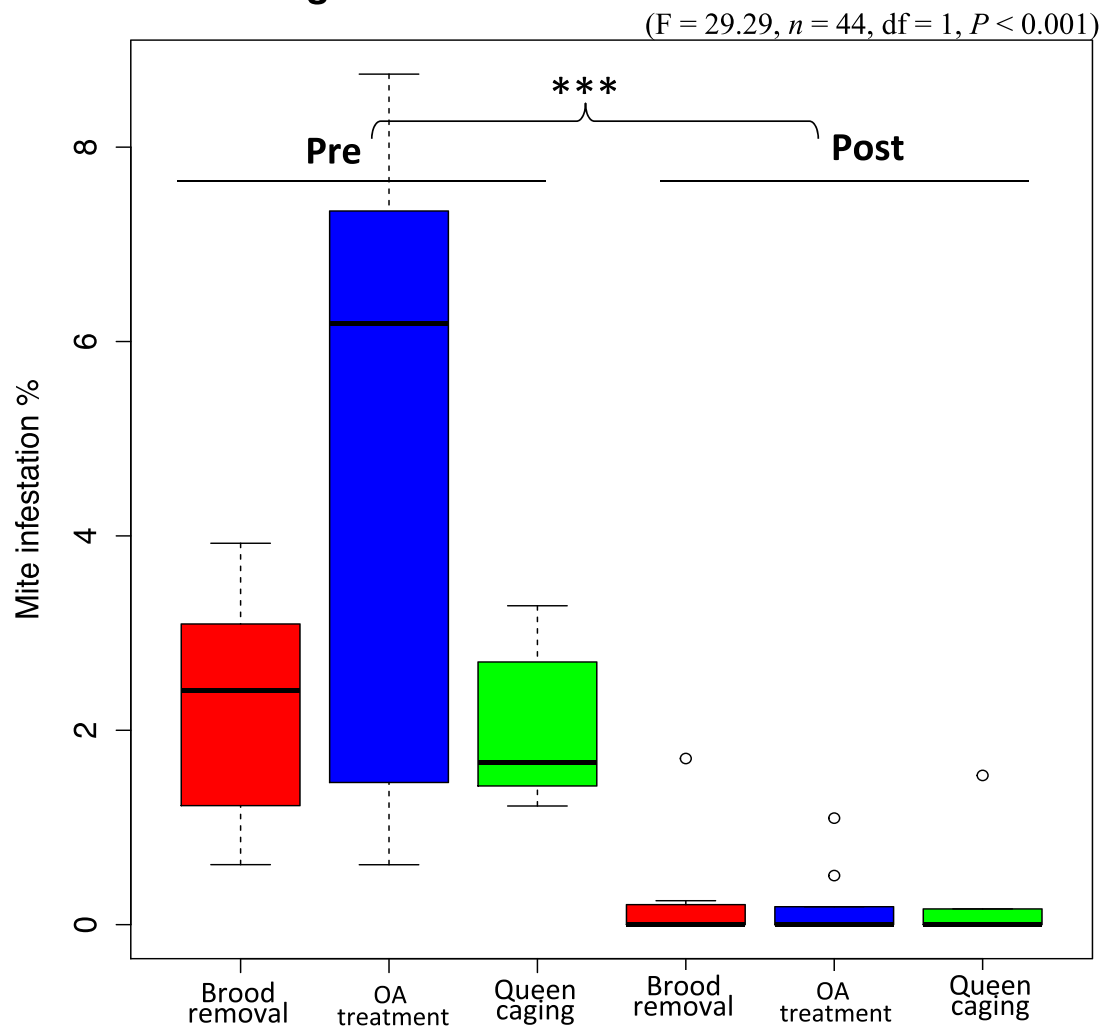

Figure 7. A comparison of the levels of varroa mite infestation on adult bees before (Pre) and after (Post) the experiment using sugar shake diagnosis, exposed by each treatment group (brood removal, OA treatment, and queen caging) and calculated as a percentage or number of varroa/100 bees.

also showed that higher mite infestation with varroa was recorded at the end of the experiment (25 May) in colonies with brood removed and immediate OA application (22 April). After this experimental treatment period, any remaining varroa mites as well as those present due to reinfestation from other colonies were controlled via Apistan ${ }^{\circledR}$ strips.

During the course of this experiment, all colonies developed normally and no abnormal bee mortalities were observed due to OA treatments, as opposed to challenges experienced by prior researchers including weakened colonies (Imdorf et al. 1997) or increased queen mortality (Higes et al. 1999). Worker bees or brood mortality could be better evaluated with further studies, adopting more accurate estimates to calculate the amount of brood and adult bees in treated colonies. In our cage experiment, the highest OA exposure was approx. $250 \mu \mathrm{g}$ per bee, which is $2.5 \times$ higher than the previously reported tolerance levels (Aliano et al. 2006). It is therefore supposed that only individual bees would be killed following direct contact exposure to OA in cage tests or colony trickling. While some bees are exposed to lethal OA doses when using the trickling method in colonies, there is very low probability that the queen would be exposed, and any individual bee mortality would not have a colony level impact. Likewise, any increased bee mortality attributed to Apistan ${ }^{\circledR}$ strips would be unimportant at the colony level, because all of our experimental colonies were treated simultaneously and the bee mortality was comparable.

The results of these experiments provide evidence that, when using appropriate beekeeping 
practices to maximize colony vigor, a beekeeper can combine applications of OA, which is nontoxic to adult workers, as demonstrated in our laboratory experiment, with either queen caging or brood removal to ensure adequate varroa control, prior to the main spring honey flow. And when considering the potential reduction of Apistan ${ }^{\circledR}$ efficacy due to resistance development in mites, the value of using such an integrated management strategy may become increasingly important.

\section{ACKNOWLEDGEMENTS}

The authors thank Trevor Mallette and Reggie Davis for their technical assistance in performing experiments and Blair Simpson for editing a draft of this manuscript. We are thankful to two anonymous reviewers for their comments and suggestions.

Contributions AG and JA conceived and designed experiment, $\mathrm{AG}$ and $\mathrm{MA}$ analyzed and interpreted the data, and $\mathrm{AG}, \mathrm{TRK}$, and $\mathrm{CW}$ wrote the manuscript.

Retrait du couvain ou mise en cage de la reine, en combinaison avec un traitement à l'acide oxalique, pour lutter contre les acariens (Varroa destructor) dans les colonies d'abeilles (Apis mellifera)

Lutte anti-acarien / cage à reine / Acari / technique du sucre glace / surveillance sanitaire

Brutentnahme bzw. Sperren der Königin in Kombination mit Oxalsäurebehandlung zur Kontrolle von Varroamilben (Varroa destructor) in Honigbienenvölkern (Apis mellifera)

Varroabekämpfung / Oxalsäure / Käfig/ Puderzucker / Acari

\section{REFERENCES}

Al Toufailia, H., Ratnieks, F.L.W. (2016). How effective is Apistan ${ }^{\circledR}$ at killing varroa? Results from a LASI trial. Bee Craft 98 (2), 7-11

Al Toufailia, H.M., Scandian, L., Ratnieks, F.L.W. (2015) (Towards integrated control of varroa: 2) comparing application methods and doses of oxalic acid on the mortality of phoretic Varroa destructor mites and their honey bee hosts. J. Apic. Res. 54 (2), 108-120

Aliano, N.P., Ellis, M.D., Siegfried, B.D. (2006). Acute Contact Toxicity of Oxalic Acid to Varroa destructor
(Acari: Varroidae) and Their Apis mellifera (Hymenoptera: Apidae) Hosts in Laboratory Bioassays. J Econ Entomol. 99, 1579-1582

Branco, M.R., Kidd, N.A.C., Pickard, R.S. (2006) A comparative evaluation of sampling methods for Varroa destructor (Acari: Varroidae) population estimation. Apidologie 37 (4): 452-461

Brødsgaard, C.J., Brødsgaard, H.F. (1998) Monitoring method as a basis for need-based control of Varroa mites (Varroa jacobsoni) infesting honey bee (Apis mellifera ) colonies, ATLA 26 (4), 413-419

Calis, J.N.M., Boot, W.J., Beetsma, J., van den Eijende, J.H.P.M., De Ruijter, A., van der Steen, J.J.M. (1999) Effective biotechnical control of Varroa, applying knowledge of brood cell invasion to trap honey bee parasites in drone brood. J. Apic. Res. 38 (1-2), 49-61

Charrière, J.D. (2001). Optimization of the oxalic acid trickling method and bee tolerability of different winter treatments: Trials in Liebefeld during the last 3 years. Meeting of the European Group for Varroa Control, York, UK.

Charrière, J.D., Imdorf, A. (2002). Oxalic acid treatment by trickling against Varroa destructor: Recommendations for use in central Europe and under temperate climate conditions. Bee World; 83 (2), 51-60

Charrière J.D., Imdorf A., Kuhn R. (2004) Honey bee tolerance to different winter treatments against Varroa, Rev. Suisse Apic. 125, 32-39

Coffey, M.F., Breen, J. (2016) The efficacy and tolerability of Api-Bioxal $(\mathbb{B}$ as a winter varroacide in a cool temperate climate. J. Apic. Res. 55(1), 65-73

Delaplane, K.S., Berry, J.A., Skinner, J.A., Parkman, J.P., Hood, W.M. (2005) Integrated pest management against Varroa destructor reduces colony mite levels and delays treatment threshold. J. Apic. Res. 44 (4), 157-162

Evans, J.D., Chen, Y.P., di Prisco, G., Pettis, J., Williams, V. (2009) Bee cups: single-use cages for honey bee experiments. J. Apic. Res. 48(4), 300-302 doi:10.3896 /IBRA.1.48.4.13.

Fakhimzadeh, K. (2000) Potential of super-fine ground plain white sugar dusting as an ecological tool for the control of varroasis in the honey bee (Apis mellifera). Am. Bee J. 140 (6), 487-491

Giacomelli, A., Pietropaoli, M., Carvelli, A., Iacoponi, F., Formato, G. (2016) Combination of thymol treatment (Apiguard $($ ) and caging the queen technique to fight Varroa destructor. Apidologie 47 (4), 606-616

Glass, G.V., Peckham, P.D., Sanders, J.R. (1972) Consequences of Failure to Meet Assumptions Underlying the Fixed Effects Analyses of Variance and Covariance. Review of Educational Research 42 (3), 237-288

González-Cabrera, J., Rodríguez-Vargas, S., Davies, T.G.E., Field, L.M., Schmehl, D., Ellis, J.D., Krieger, K., Williamson, M.S. (2016) Novel Mutations in the Voltage-Gated Sodium Channel of PyrethroidResistant Varroa destructor Populations from the Southeastern USA. PLoS ONE 11(5): e0155332. doi:10.1371/journal.pone.0155332 
Gregorc, A., Planinc, I. (2001) Acaricidal effect of oxalic acid in honey bee (Apis mellifera) colonies. Apidologie 32 (4), 333-340

Gregorc, A., Planinc, I, (2004) Dynamics of falling Varroa mites in honeybee (Apis mellifera) colonies following oxalic acid treatments. Acta Vet. Brno 73 (3), 385-391

Gregorc, A., Smodiš Škerl, M.I. (2007) Toxicological and immunohistochemical testing of honeybees after oxalic and rotenone treatments. Apidologie, 38(3), 296-305

Gregorc, A., Adamczyk, J., Kapun, S. Planinc, I. (2016) Integrated varroa control in honey bee (Apis mellifera carnica) colonies with or without brood. J. Apic. Res. 55 (3), 253-258

Harwell, M.R., Rubinstein, E.N., Hayes, W.S., Olds, C.C. (1992) Summarizing Monte Carlo Results in Methodological Research: The One- and Two-Factor Fixed Effects ANOVA Cases. J. Educ. Behav. Stat. 17(4), 315-339

Higes, M., Meana, A., Suárez, M., Llorente, J. (1999) Negative long-term effects on bee colonies treated with oxalic acid against Varroa jacobsoni Oud. Apidologie, 30, 289-292

Imdorf, A., Charriere, J.D., Maquelin, C., Kilchenmann, V., Bachofen, B. (1996) Alternative Varroa control. Am. Bee. J. 136 (3), 189-93

Imdorf, A., Charriere, J.D., Bachofen, B. (1997) Efficiency checking of the Varroa jacobsoni control methods by means of oxalic acid. Apiacta 32 (3), 89-91

Liebig, G. (1998) Zur Eignung des Aufträufelns von Oxalsäure für die Varroabehandlung. Dtsch. Bien. J. 6, 224-226

Lix, L.M., Keselman, J.C., Keselman, H.J. (1996) Consequences of Assumption Violations Revisited: A Quantitative Review of Alternatives to the One-Way Analysis of Variance $F$ Test Review of Educational Research 66(4), 579-619

Macedo, P. A., Ellis, M. D. (2000) Detecting and assessing Varroa mite infestations by using powdered sugar to dislodge mites. Proceedings of the American Bee Research Conference. Am. Bee J. 140(11), 906

Milani, N. (1990) Mortalità naturale di Varroa jacobsoni Oud. e livello di infestazione degli alveari. Apicoltura 6, 1-9

Milani, N. (1999) The resistance of Varroa jacobsoni Oud. to acaricides. Apidologie 30 (2-3), 229-234
Milani, N. (2001) Activity of oxalic acid and citric acids on the mite Varroa destructor in laboratory assays, Apidologie 32 (2), 127-138

Mutinelli, F., Baggio, A., Capolongo, F., Piro, R., Prandin, L., Biasion, L. (1997) A scientific note on oxalic acid by topical application for the control of varroosis. Apidologie 28(6), 461-462

Nanetti, A. (1999) Oxalic acid for mite control - results and review. Coordination in Europe of research on integrated control of Varroa mites in honey bee colonies. Commission of the European communities 7-14

Nanetti, A., Higes, M., Baracani, G., Besana, A. (2012) Control de la varroa con ácido oxálico en combinación con la interrupción artificial de la puesta de cría. Proceeding of II Congreso Ibérico de Apicultura, Guadalajara, Spain, October 18-20

Nanetti, A., Büchler, R., Uzunov, A., Gregorc, A. (2016). Coloss - varroa control taskforce, brood interruption study $2016 / 2017$. http://www.coloss. org/taskforces/varroacontrol/protocols-brood-interruption-varroa-task-coloss-2016-jan-final

Pietropaoli, M., Giacomelli, A., Milito, M., Gobbi, C., Scholl, F., Formato, G. (2012) Integrated pest management strategies against Varroa destructor, the use of oxalic acid combined with innovative cages to obtain the absence of brood. Eur. J. Integr. Med. 15, 93

R Core Team. (2011) R: A language and environment for statistical computing. R Foundation for Statistical Computing, Vienna.

Rosenkranz, P., Aumeier, P., Ziegelmann, B. (2010) Biology and control of Varroa destructor. J. Invertebr. Pathol. 103 (1), 96-119

Ruijter, A. (1994) Issues in the control of Varroa infestation. New perspectives on Varroa. Ed. Andrew Matheson, IBRA Cardiff, 24-26

Smodiš Škerl, M. I., Nakrst, M., Žvokelj, L., Gregorc, A. (2011) The acaricidal effect of flumethrin, oxalic acid and amitraz against Varroa destructor in honey bee (Apis mellifera carnica) colonies. Acta veterinaria Brno, $80(1), 51-56$

Toomemaa, K., Martin, A. J., Williams, I. H. (2010) The effect of different concentrations of oxalic acid in aqueous and sucrose solution on Varroa mites and honey bees. Apidologie 41 (6), 643-653.

Wallner, K. (1999) Varroacides and their residues in bee products. Apidologie 30 (2-3), 235-248 